\title{
Justiça e sustentabilidade: a destinação dos royalties de petróleo
}

\author{
HIRDAN KATARINA DE MEDEIROS COSTA \\ e EDMILSON MOUTINHO DOS SANTOS
}

\section{Introdução}

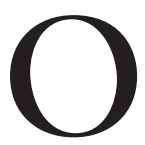

PRESENTE artigo objetiva introduzir e discorrer sobre o princípio da justiça intra e intergeracional para fins da normatização da destinação das rendas decorrentes da produção de petróleo e de gás natural, que adiante serão denominadas rendas de hidrocarbonetos. A questão aqui discutida aplica-se às rendas geradas a partir de atividades minerais como um todo. Porém, o trabalho concentra suas reflexões nas rendas de hidrocarbonetos, também conhecidas como participações governamentais (especificamente royalties e participação especial $)^{1}$. Em cada nação, estas podem adquirir diferentes denominações e seguir regras diversas.

A contribuição teórica do artigo se centra na construção do princípio da justiça intra e intergeracional, a partir da leitura e da análise dos defensores da alocação das rendas de hidrocarbonetos em políticas públicas de efetivação de direitos fundamentais. Consideram-se, também, autores que advogam pela aplicação das rendas de recursos exauríveis em capital reprodutível, assegurador de benefícios para as gerações futuras.

Examinam-se similaridades e diferenças argumentativas dessas correntes para propor um caminho de destinação das rendas de hidrocarbonetos que permita contribuir no financiamento da continuidade da qualidade da vida humana no globo terrestre. Nesse sentido, levantam-se pontos de reflexão acerca de como as rendas de hidrocarbonetos podem colaborar para a mitigação dos impactos causados ao meio ambiente pela ação do ser humano, bem como qual a possível relação entre destinação das rendas de hidrocarbonetos, a noção de sustentabilidade e o princípio da justiça intra e intergeracional.

Para tanto, na primeira seção foram introduzidas as visões dos teóricos, que tratam do tema destinação das rendas de recursos naturais exauríveis, com o objetivo de construção da proposição argumentativa de convergência dos diferentes pontos conceituais. A segunda seção mostra a discussão teórica, bem como encaminha o conceito do princípio da justiça intra e intergeracional para a seara da sustentabilidade. A terceira seção aprofunda a abordagem entre desti- 
nação das rendas, direitos fundamentais e sustentabilidade incorporada ao princípio da justiça intra e intergeracional. Na quarta seção, breves considerações finais do assunto são expostas.

\section{Convergência entre justiça intra e intergeracional}

Quando se fala em recursos naturais exauríveis integrantes de uma cesta básica de consumo, como conciliar as necessidades das correntes gerações com as das futuras? O usufruto de alguns recursos pode encontrar limitações temporais em virtude de sua inerente esgotabilidade, o caso de hidrocarbonetos. $\mathrm{O}$ desenvolvimento ligado ao consumo de recursos naturais para prover as gerações atuais pode causar, no futuro, impossibilidade de gerações vindouras usufruírem desses mesmos recursos. Ao se observar que alguns recursos naturais são ou se tornam escassos, resta refletir sobre a escolha de se consumir tudo hoje ou de se reservar algum tipo de estoque para as gerações futuras.

Ao enfocar o uso das rendas derivadas das atividades minerais, Hartwick (1977) demonstrou que o investimento em bens de capital reprodutível poderia atender às necessidades de desenvolvimento das futuras gerações. ${ }^{2}$ Resolver-se-ia, em princípio, o problema ético entre gerações, quando as populações atuais consomem apenas uma parcela do capital remanescente da produção do recurso natural.

Hartwick (1977, p.974), por meio da função tecnológica de Cobb-Douglas, estabeleceu a seguinte regra, conhecida como Regra de Hartwick: o investimento da renda gerada na atual exploração de recursos naturais não renováveis em capital reprodutível implica um consumo per capita constante. Apesar da ausência do recurso natural em si, os investimentos realizados, com as rendas minerais geradas, podem garantir uma riqueza futura constante, permitindo a manutenção da renda individual e da riqueza social. Contudo, quando se visualiza a destinação das rendas de hidrocarbonetos nos países em desenvolvimento, que apresentam elevados graus de desigualdades sociais, cabe indagar se a regra de Hartwick é satisfatória para não reproduzir tais desequilíbrios e injustiças sociais no futuro. Além disso, nos debates que se estabelecem a cada momento histórico, em relação à partilha das rendas minerais geradas, o consumo do capital remanescente é sempre considerado essencial para a população atual usufruir maiores possibilidades de desenvolvimento humano. Com isso, pode-se colocar o seguinte ponto: qual seria o equilíbrio entre gastos presentes e investimentos (com potencial de financiar gastos futuros)?

Após o estudo clássico de Hartwick, o assunto tem sido abordado em diferentes momentos, dentro de realidades nacionais distintas. No Brasil, após a década de 1990, quando as receitas provenientes da exploração econômica de hidrocarbonetos atingiram patamares consideráveis em sua relação percentual com o orçamento público de certas localidades beneficiárias, o tema adentrou definitivamente na agenda política nacional.

Pacheco (2007), em análise do caso brasileiro, salienta que nas localidades 
por ele estudadas não foram verificadas ações concretas para a promoção de um projeto de sustentabilidade, de promoção de justiça intergeracional e de diversificação da base produtiva local.

Serra $(2007$, p.2-3) crítica a realidade brasileira de descentralização da aplicação das rendas de hidrocarbonetos. Para o autor, os estados e municípios beneficiários não possuem diretrizes de lei quanto ao uso dos recursos. Assim, sem a devida cautela na aplicação desse montante, decisões que promovam o consumo presente inibem o investimento em setores que possam lidar com a posterior exaustão desses recursos minerais. Ainda, Serra $(2005$, p.208) salienta que "o repasse de royalties aos municípios, da maneira que é feito, pode ser entendido como um dos principais golpes na construção de um fundo em prol da justiça intergeracional". Para o autor, uma política de desenvolvimento de fontes alternativas de energia seria, por exemplo, adequada "dentro da perspectiva moral que valoriza a justiça intergeracional: a finita riqueza mineral, extraída hoje, representa um saque feito ao patrimônio das futuras gerações, as quais precisam ser compensadas". Nessa visão, as gerações futuras "pobres" em petróleo, por meio de compensação, teriam desenvolvidas outras formas de geração de energia.

Carvalho (2008, p.81-2), em estudo sobre relação entre a exploração do petróleo e aspectos éticos, como justiça e equidade intergeracional, ao enfocar a realidade brasileira, defende a aplicação das rendas de hidrocarbonetos de modo que as gerações futuras possam se sustentar sem a presença desse recurso natural exaurível. A autora ressalta a importância de diversidade de destinação das rendas em políticas públicas que incentivem a geração de renda futura pela diversificação da economia, mediante o investimento em saúde, educação e infraestrutura, bem como em políticas de pesquisa e desenvolvimento que promovam a diversificação da matriz energética.

Quando os autores expõem a necessidade de investimentos em saúde, educação e infraestrutura, bem como em políticas de sustentabilidade e de diversificação econômica, ocorre uma nítida aproximação entre a perspectiva econômica e a teoria dos direitos fundamentais. Torronteguy $(2009$, p.84) vincula a aplicação de royalties à efetivação de direitos fundamentais sociais, tais como os direitos à saúde, à educação, à moradia, à assistência social, ao meio ambiente $\mathrm{e}$ proteção à infância, à adolescência e aos idosos. ${ }^{3}$ Para a autora, o ordenamento jurídico não pode ficar a mercê de legislações estritas, restritivas e omissas, "que promovam algum retrocesso em termos sociais e fomentem ainda mais o atual modelo de desenvolvimento econômico".

Bregman $(2007$, p.56) aponta que "as políticas voltadas para a promoção da justiça intergeracional se confundem com aquelas voltadas para o desenvolvimento". Permite-se, então, levantar a reflexão da ligação entre políticas que considerem as necessidades das gerações atuais e futuras.

Aponta-se, dessa forma, que as semelhanças entre as posições dos autores acima referenciados convergem para um discurso que envolve a destinação das 
rendas para diversificação e sustentabilidade econômica, por meio de investimento em infraestrutura básica, de formação de mão de obra através da educação e do reforço da qualidade de vida com investimentos em saúde. Também, destaca-se a contínua expansão de concepções baseadas em investimentos em fontes de energia alternativas ao petróleo.

A diferença poderia ser apontada a partir de uma incorporação da efetivação de direitos fundamentais sociais, que não somente educação e saúde na seara da destinação desses recursos. Ademais, na literatura consultada não se constatou a construção de uma relação entre os benefícios para as gerações futuras a partir do acréscimo de rol de áreas de destinação das rendas baseadas na efetivação de direitos fundamentais sociais das gerações atuais.

A despeito da importância teórica do desenvolvimento da justiça intergeracional, outras lacunas podem, ainda, ser apontadas nos textos selecionados: quem seriam as gerações futuras? Aquelas que nascerão após a exaustão total das reservas do petróleo? Ou aquelas que nascem durante o processo de exaustão das reservas? Realmente, faz-se necessário a humanidade caminhar para a exaustão das reservas de hidrocarbonetos ou propor a substituição gradativa dessa fonte de energia por outras formas que sustentem a qualidade de vida do globo terrestre? Quais seriam os direitos das gerações futuras relacionadas ao meio ambiente ecologicamente equilibrado diante dos atuais uso e manejo dos recursos naturais realizados pelas presentes gerações?

Nusdeo (2010) acrescenta, também, a discussão sobre a justiça ambiental, que propugna o alcance uniforme dos bens ambientais e dos benefícios da aplicação concreta do desenvolvimento sustentável para todos os membros da atual sociedade, bem como que o compartilhamento dos ônus do progresso seja suportado por toda a coletividade, sem discriminação por questões de ordem racial, étnica ou econômica. A justiça ambiental surgiu a partir da experiência inicial dos movimentos sociais dos Estados Unidos, em que além de desigualdades sociais e econômicas, as disparidades ambientais, também, passaram a ser alvo de reivindicação dos cidadãos pobres e de etnias socialmente discriminadas e vulnerabilizadas (Herculano, 2011).

Assim, decisões de agentes políticos e econômicos quanto ao local de instalação de indústria com efluentes poluentes, exemplo de uma refinaria de petróleo, deveriam passar a levar em conta o equitativo compartilhamento dos passivos ambientais por toda a sociedade e no presente, e não apenas a um grupo discriminado ou a gerações futuras. Sendo assim, no âmbito de diálogo entre o princípio da justiça intergeracional e a justiça ambiental, é fundamental considerar a perspectiva temporal e incluir como responsabilidade a ser vivenciada no presente a efetivação do direito ao meio ecologicamente equilibrado, e não deixar que o ônus do progresso seja suportado, também, pelo futuro.

Perante esse argumento, qual o sentido de direcionar as rendas de hidrocarbonetos para investimentos em capital reprodutível ou alocação em poupança 
pública diante de um cenário presente de desigualdade e de degradação ambientais e de extinção de inúmeras espécies vegetais e animais? Existem lacunas no alcance de medidas para dar concretude às escolhas de gastos, por exemplo, como proporcionar a justiça, também, para as gerações atuais, diante da nítida desigualdade social, econômica e ambiental? Como proceder com o gasto e/ou o investimento em efetivação de direitos fundamentais conjugados a políticas desenvolvimentistas baseadas na diversificação e na sustentabilidade econômica, energética e ambiental? Faz sentido separar políticas e planejamentos públicos para as atuais e para as futuras gerações?

É possível notar uma ausência de abordagem epistemológica da justiça intergeracional nas obras dos autores acima citados, o que merece reparo. Com isso, além de referências a gerações vindouras, pode-se começar a correlacionar a justiça intergeracional com a necessidade de efetivação dos direitos sociais, econômicos e de cooperação das atuais gerações, os quais incluem, também, a abordagem dada pela justiça ambiental. A justiça intra e intergeracional envolve os direitos das futuras gerações a encontrar as plenas condições de seu desenvolvimento no globo terrestre, inclusive, com os positivos reflexos das conquistas de evolução das atuais gerações em termos de criação equitativa de oportunidades pautadas pela preservação e conservação ambientais. Sendo assim, é claramente perceptível que as condições herdadas pelas gerações futuras dependerão fortemente das qualidades de vida usufruídas pelas gerações atuais, incluindo-se os funcionamentos e as capacidades vivenciadas pela atual comunidade, assim como as consequências das atividades empregadas sobre o meio ambiente.

Nessa esteira de raciocínio, pode-se afirmar que uma regulação da aplicação de rendas de hidrocarbonetos deve conter os excessos e os abusos do ponto de vista econômico, ambiental, político e social, servindo como norteador da discricionariedade do administrador público, e como diretriz de aplicação do direito ao caso concreto pelo judiciário. Atuar, assim, sobre os direitos das atuais e das futuras gerações permite seguir um escopo ético-normativo, criador de uma justiça social, econômica e ambiental que considere as consequências das escolhas atuais.

Identificando a regra de Hartwick, autores são pacíficos em reconhecer que as jazidas minerais economicamente viáveis são ativos e oportunidades, das quais os países produtores, sabiamente, podem se valer para atingir níveis razoáveis de desenvolvimento e de erradicação da pobreza. Sendo assim, as necessidades das atuais e das futuras gerações estariam atendidas com investimentos em capitais físico, humano, tecnológico e institucional (Davis; Tilton, 2005, p.237). Dentro dessa lista construída por Davis e Tilton (2005), há de incluir as necessidades de despesas e de investimentos em soluções ambientais, com fins de atingir a justiça ambiental, vinculando-as ao conceito de sustentabilidade, ou seja, que se repensem as decisões diante de determinado impacto ambiental, caso a resolução seja colocada para o futuro. 
Segundo tais critérios de aplicação de recursos, a efetivação de direitos fundamentais, também, permite alcançar a justiça entre as necessidades das atuais e das futuras gerações, no sentido de possibilitar a redução da pobreza sistêmica, que inclui não somente a ausência do gozo de bens materiais, mas as impossibilidades de usufruto de bens intelectuais, como a educação, o que corresponderia ao investimento em capital humano. Nessa linha de argumentação, defende-se a continuidade lógica entre a justiça intra e intergeracional, considerando que o conteúdo de justiça intrageracional irá desencadear relações lógicas causais na justiça intergeracional. Assim, políticas públicas pautadas pela construção de uma justiça para as atuais gerações, também, devem prever a extensão de impactos para as futuras gerações.

Outrossim, as interações entre tais tipos de justiça mostram que a forma adequada de compreendê-las é através de uma unicidade. Com tal sentido, enxerga-se a justiça intra e intergeracional como uma única justiça, de similar conteúdo e igual necessidade de concretude, porém com diversas formas de efetivação. Com tais ponderações, a justiça intra e intergeracional deverá ser parâmetro de destinação das rendas derivadas da extração econômica de hidrocarbonetos. Portanto, diferenciações entre as atuais e futuras gerações, ao se adotar uma visão unitária, são ilusórias. Uma comparação entre os teóricos estudados nos parágrafos anteriores remonta à construção de uma visão clara da necessidade de alcance da justiça social, econômica e ambiental nas atuais gerações formadoras da base inexorável das gerações vindouras, o que logicamente traduz as raízes humanas de ancestralidade e de corresponsabilidade dentro de uma percepção de comprometimento social.

Sendo assim, qual o sentido de se separar os indivíduos entre os de gerações atuais e os que pertencerão a gerações futuras? Do ponto de vista epistemológico, não faz sentido, porque considerando a continuidade da vida no globo terrestre, os seres humanos são únicos e totalmente corresponsáveis por suas criações, independentemente do conceito de gerações. Ademais, qual o efeito possível que essa separação ocasiona nas atitudes da geração atual? Um dos efeitos é o distanciamento dos problemas criados na atualidade, que podem ficar para as gerações futuras resolverem, em virtude de justificativas pautadas por progressos vindouros. Porém, quando o ser humano enxerga que ele próprio pode ser prejudicado, fica mais perceptível sua responsabilidade e sua atitude necessária de modificação do quadro por ele mesmo criado.

A convergência entre justiça nas atuais e nas futuras gerações diante de uma abordagem jurídica e econômica mostra, portanto, a importância dos seus desdobramentos na seara do discurso dos direitos, das políticas, dos programas e dos planejamentos públicos adequados para efetivá-los, visto que juízos avaliatórios ético-econômicos servirão como fundamento para a real vida do jurídico, ou seja, no momento de concretização da norma jurídica, que foi delineada e interpretada seguindo determinados juízos avaliatórios. 
Assim, é ilusório esgotar recursos naturais exauríveis e/ou adotar parâmetros de desenvolvimento que levarão à exaustão da qualidade de recursos naturais renováveis em razão de valores e de necessidades construídas para as atuais gerações, a partir de adoção de um nítido interesse político de influenciar os resultados de eleições e de exercer um poder hegemônico sobre a população atual e local, que se sente imediatamente abastecida de suas necessidades manipuladas, perpetuando-se mecanismos cíclicos de dominação política e econômica sob os territórios.

Não se trata de entender que as rendas decorrentes da extração econômica de hidrocarbonetos resolverão todos os problemas de certa sociedade, mas de aproveitar a existência desse recurso público financeiro para destinar tais rendas de forma a criar e revisar conceitos e parâmetros desenvolvimentistas atuais para possibilitar a continuidade da vida com qualidade sobre o planeta Terra. Portanto, o princípio da justiça intra e intergeracional absorve a justiça intergeracional para construir a percepção da unicidade da espécie humana e da sua relação com o seu território e/ou com a natureza, o que inclui o uso, o manejo e a gestão dos recursos naturais.

\section{A perspectiva de exaustão das reservas de hidrocarbonetos e o conceito de sustentabilidade: a relação com o princípio da justiça intra e intergeracional}

A necessidade de preparação da sociedade para o processo de exaustão das reservas de hidrocarbonetos traz à tona três principais problemáticas: a primeira relaciona-se com o término de um específico fluxo de riquezas alavancado pelo desenrolar dessa indústria; a segunda refere-se ao incremento da utilização de fontes alternativas em substituição aos hidrocarbonetos como fonte primária de geração de energia; e a terceira é atinente a necessidades reais dos seres humanos e sua relação com o planeta Terra. Esses pontos envolvem intuitivamente a questão pertinente à sustentabilidade. Todavia, o que é sustentabilidade?

Moutinho dos Santos (2004) parte da definição do verbo "sustentar" dentro do vernáculo para demonstrar que a riqueza linguística ocasiona uma difícil tarefa de construir uma definição direta e simples de sustentabilidade. Para o autor, o substantivo sustentabilidade, desde seus primórdios, tem se relacionado a um estado ou condiciona uma dinâmica, que pode ser mantido por um período indefinido, mas longo, de tempo. Tal percepção se aproxima de conceito como o utilizado em Vargas (1996, p.297), que correlaciona sustentabilidade à adoção, pela sociedade, de um estilo de vida que preserve a diversidade dos sistemas de vida, levando a garantir a operação continuada do processo evolutivo multifacetado. Barbieri (2005, p.39) diz que o "conceito tradicional de sustentabilidade tem sua origem nas Ciências Biológicas e aplica-se aos recursos renováveis, principalmente, os que podem se exaurir pela exploração descontrolada, como são os casos dos cardumes de peixes e das espécies vegetais das florestas naturais".

Ainda, Moutinho dos Santos (2004, p.6) explica que em outras aborda- 
gens, interpreta-se a sustentabilidade como uma descrição de processos que estão continuamente evoluindo, o que expõe as preocupações com as taxas das mudanças. E, dentro dessa sistemática, o desenvolvimento sustentável passa a ser peça-chave. O autor, também, faz referência ao princípio da equidade intergeracional, quando aborda uma acepção mais completa da sustentabilidade, aludindo ao uso ou à gestão de recursos naturais a uma taxa aceitável, que permita a satisfação das necessidades das atuais gerações e proteja os interesses das gerações do futuro. Conforme esse autor, a sustentabilidade requisita um entendimento simultaneamente de três dimensões: "ambiental, econômico e social das necessidades das comunidades (e através de suas gerações)" (Moutinho dos Santos, 2004, p.6).

Dentro da dimensão ambiental, Ribeiro $(2010$, p.70) pontua a sustentabilidade como a "capacidade de carga" de o planeta suportar a reprodução da vida. Visão que se aproxima da exposta em Carvalho (2009), que coloca como condição essencial para a sustentabilidade a efetiva compatibilização do crescimento do uso de recursos naturais com a capacidade do ambiente de renová-los e de reciclar seus rejeitos.

Veiga (2006, p.109) diz que a noção do que é sustentável envolve, basicamente, três padrões de resposta, correspondente a duas teses extremas criadoras de um impasse e um anátema no âmbito da retórica científica, e uma terceira corrente com discurso eclético, mas que faz parte da retórica político-ideólogica. Assim, de um lado, autores que não acreditam na existência de dilema entre conservação ambiental e crescimento econômico, apoiando sua possível conciliação. E, de outro lado, estariam teóricos, que negam tal possibilidade de convergência entre conservação ambiental e crescimento econômico; por exemplo, Georgescu-Roegen defende que o desenvolvimento com o decréscimo do produto deve ser apoiado pela humanidade. E, ainda dentre os céticos, Daly aponta a "condição estacionária" como alternativa à decadência ecológica, com a melhoria da economia em termos qualitativos, ao se verificar, por exemplo, a migração de energia fóssil para energia limpa (Veiga, 2006, p.109-13).

Veiga (2006, p.164-5), contudo, seguindo a dificuldade conceitual apontada por Moutinho dos Santos (2004), acrescenta que:

acontece que estão justamente nas fraquezas, imprecisões e ambivalências da noção de sustentabilidade as razões de sua força e aceitação quase total [...] sendo uma questão primordialmente ética, só se pode louvar o fato da ideia de sustentabilidade ter adquirido tanta importância nos últimos vinte anos [...]. A sustentabilidade não é, e nunca será, uma noção de natureza precisa, discreta, analítica ou aritmética.

Souza (2002, p.7) diz que a sustentabilidade é uma metáfora poderosa e que acoberta o tema sobre o qual precisamos tratar, falar, discutir: a desigualdade. Mendonça (2005, p.71) lembra que "falar de meio ambiente significa, antes de tudo, lutar para o equacionamento de graves problemas sociais que tão mar- 
cadamente caracterizam o espaço geográfico nacional". Santos (1992, p.97) correlaciona os padrões de vida adotados pela humanidade e a própria necessidade de se afirmar mudanças que protejam e efetivem o direito ao desenvolvimento, ao meio ambiente equilibrado e à propriedade sobre o patrimônio comum da humanidade.

Longe de um consenso, os debates continuam e, hodiernamente, como explica Sachs (2006) prefaciando a obra de Veiga (2006), o desenvolvimento sustentável deveria, a rigor, ter a adjetivação "desdobrada em socialmente includente, ambientalmente sustentável e economicamente sustentado no tempo". Todavia, Sachs (2006) alerta que "a problemática do desenvolvimento passou de moda e o seu status acadêmico é cada vez mais marginal".

A noção de sustentabilidade, também, envolve a reflexão da desigualdade e da ideologia da separação criada pelo homem, que, ao esquecer sua unicidade, fica fragmentado e não consegue obter respostas que deem conta da atual realidade. Com isso, ao se adotar o princípio de justiça intra e intergeracional, dentro do viés de unicidade da espécie humana em suas sucessivas gerações, proporciona-se a visão de integralidade do ser humano. A ideia de fragmentação já não deve encontrar espaço na sociedade, mesmo na perspectiva temporal que separa as gerações.

Dentro dessa completude, o princípio da justiça intra e intergeracional correlaciona a ideia de sustentabilidade à efetivação de direitos fundamentais civis, sociais e de cooperação, que abarcam a perspectiva da justiça ambiental, aos investimentos em diversificação econômica e aos usos de outras fontes de energia que respeitam o ambiente e se espraiam para uma proposta de continuidade da vida do globo. Por tal motivo, quando da escolha da destinação das rendas de hidrocarbonetos, é fundamental refletir na sustentabilidade, que se estende harmoniosamente do local para o global, e permite, conforme explicado em Souza (2002, p.9-11), o uso de metodologia pautada pela compreensão do funcionamento do território que direcione as prioridades em investimentos, bem como o entendimento das necessidades e do nível de qualidade de vida da população que vive em certo território, além do exame das necessidades progressivas e de seu crescimento populacional.

\section{Reflexão acerca das relações existentes entre necessidades humanas, direitos fundamentais, expansão das dimensões da sustentabilidade e o princípio da justiça intra e intergeracional}

O discurso dos direitos fundamentais em suas diversas dimensões ${ }^{4}$ é pautado pela assunção da percepção acerca do incremento das necessidades humanas, sejam elas materiais, valorativas, morais e espirituais. Como Bobbio (2004, p.9) sugere, a "linguagem dos direitos tem indubitavelmente uma grande função prática, que é emprestar uma força particular às reivindicações dos movimentos que demandam para si e para os outros a satisfação de novos carecimentos materiais e morais".

Bobbio (2004, p.18) lembra que esses direitos são variáveis e se modificam 
constantemente, a partir das próprias condições históricas, ou da mudança das necessidades e dos interesses, das classes de poder, dos meios disponíveis para a sua realização ou das transformações técnicas. Por exemplo, na Grécia antiga, a liberdade era relativa até para o cidadão grego, porquanto a cidadania ainda significava somente o poder de participar da vida política e administrativa das cidades-Estado. O posterior esquecimento de conceitos de cidadania em Roma antiga e na Idade Média ocasionou a sua retomada somente quando da Revolução Francesa de 1789, que instituiu os direitos de liberdade. No início do século XXI, o conceito de cidadania vivencia uma expansão, e significa "ser partícipe da vida política como decorrência direta e imediata do acesso efetivo aos direitos fundamentais, sejam eles de primeira, de segunda, ou de terceira dimensão" (Oliveira; Guimarães, 2004, p.84-6).

Efetivamente, quando se pensa em liberdade, e se ressalta, nesse momento, a ligação desse tema com a proposta conceitual de Sen (2000), não basta apenas disponibilização das liberdades negativas, ou seja, os direitos fundamentais de primeira dimensão (direitos civis e políticos), imprescindível é a existência de condições materiais que possibilitem as qualidades reais do viver no espaço geográfico, ou seja, as liberdades positivas, que podem ser entendidas como bases para os direitos fundamentais de segunda dimensão consistentes "nos direitos sociais, culturais, econômicos, bem como os direitos coletivos ou de coletividades" (Bonavides, 2010, p. 64).

Com o evolver histórico, contudo, foram surgindo novas necessidades e problemáticas no seio da humanidade, que ocasionaram a emergência dos direitos fundamentais de terceira dimensão baseados no direito ao desenvolvimento, à paz, ao meio ambiente e à comunicação (Bonavides, 2010, p.568) como novos pontos para o século XXI. Dentro dessa perspectiva, Menon (1992, p.124) argumenta sobre a ligação intrínseca existente entre os temas: melhoria do meio ambiente, atenuação da pobreza, redução do crescimento populacional e novas abordagens que proporcionem os bens e serviços que a sociedade necessita e a que aspira.

Dornelas e Brandão (2011) analisam o crescente debate sobre implementação de direitos das gerações futuras e da justiça intergeracional como assuntos correlatos à problemática da aplicação do princípio do desenvolvimento sustentável e da afirmação da justiça ambiental. Esta última pode ser vista como inserta no rol de direitos fundamentais de terceira dimensão, consistente na valorização da distribuição de benefícios e de prejuízos gerados pelos agentes humanos com fins de, em parte, qualificar as externalidades entre lugares e grupos populacionais (Jiménez, 2010). Fyfe (1997, p.187), nessa linha, aborda que "a superfície deste planeta e nossos sistemas de hidrosfera, atmosfera, biosfera devem ser administrados com grande cuidado, se quisermos que todas as pessoas desfrutem sua experiência no planeta”.

Sachs (2008, p.2-6), ao examinar relação entre os direitos humanos e o 
desenvolvimento considerado como expansão dos direitos positivos na visão de Sen (2000), diz que esses temas ocupam posição central nas preocupações das Nações Unidas. E ao substantivo desenvolvimento foram acrescidos inúmeros adjetivos como econômico, social, cultural, político, sustentável e humano para adentrar na problemática da plena realização dos homens e das mulheres ao invés de multiplicação de bens econômicos. Ainda, Sachs (2008) explica que as questões surgidas, diante da realidade social e ecológica vivenciadas pela humanidade no final do século XX, têm ocasionado a revisão de paradigmas baseados na lógica do mercado para uma nova direção voltada às lógicas das necessidades.

As necessidades humanas são simples, intuitivas, valorativas e expansivas. O ser humano sente fome,${ }^{5}$ sensações de calor e de frio, de abrigo, de conhecimento, de amor, de afeto, de abertura para o novo, do criativo, de força, de coragem, de colocar em prática o conhecimento, de se conectar ao eu interior, à espiritualidade e à coletividade a qual faz parte. As necessidades humanas são belas e direcionadas à expansão da consciência humana e do eu interior individual (Przepiorka, 2010).

Essa simplicidade questiona o conceito e a ideia construída pelo modelo de produção de até então. Nesse viés, Veiga (2006, p.194) fala que nos países chamados de primeiro mundo a lógica de produzir mais e melhor já foi rompida, as necessidades básicas dessas populações já estão atendidas, "e muitas das necessidades ainda insatisfeitas não exigem que se produza mais, mas sim que se produza de outra maneira, outra coisa ou até se produza menos. É particularmente o caso do ar, da água, do espaço, do silêncio, da beleza, do tempo, dos contatos humanos".

Conforme apresenta Sen (2000, p.9), contudo, o mundo está repleto de privação, destituição e opressão extraordinárias: persistência da pobreza e de necessidades essenciais não satisfeitas, fomes coletivas e crônicas disseminadas, violação de liberdades políticas e formais, negligência diante dos interesses e da condição de agente das mulheres e ameaças cada vez mais graves ao meio ambiente e à sustentabilidade da vida econômica e social. Por isso que, quando Sen (2000) defende a primazia das liberdades substantivas, ele procura mostrar a capacidade de cada indivíduo para levar o tipo de vida que possui razão para valorizar. E, por tal motivo, chama a atenção para a existência de diversas formas de liberdade para ultrapassar as problemáticas por ele apontadas. O que demanda a condição de agente de cada um diante das oportunidades sociais, políticas e econômicas substantivamente existentes. Com isso, Sen (2000) argumenta que a expansão da liberdade das pessoas é favorável à responsabilidade individual e ao comprometimento social. E o desenvolvimento é um "compromisso muito sério com as possibilidades de liberdade" (Sen, 2000, p.337).

O acréscimo de adjetivos ao desenvolvimento, então, traduz uma realidade multiforme e desigual composta de campos econômicos, sociais, culturais, 
políticos, sustentáveis e humanos, onde as necessidades humanas persistem de maneiras distintas ao redor do mundo e acarretam defesas direcionadas para efetivação de direitos fundamentais expansivos, ${ }^{6} \mathrm{em}$ constante evolução e que englobam em sua agenda os problemas relacionados ao desenvolvimento, ao meio ambiente, à justiça ambiental e à sustentabilidade. Barbieri (2005, p.37), nessa linha, aponta que a sustentabilidade passa a incorporar o significado de manutenção e conservação ab aeterno dos recursos naturais, porém para "isso exige avanços científicos e tecnológicos que ampliem permanentemente a capacidade de utilizar, recuperar e conservar esses recursos, bem como novos conceitos de necessidades humanas para aliviar as pressões da sociedade sobre eles". E, esses novos conceitos de necessidades humanas, os avanços vislumbrados estariam, inicialmente, dentro de perspectivas valorativas individuais e coletivas.

Então, mudanças de paradigmas e revisão de atitudes, certamente, estão dentro da íntima relação entre necessidades humanas, direitos fundamentais e sustentabilidade. Todavia, como explicado no item anterior, existe uma vagueza na definição de sustentabilidade, que permite sua expansão contínua, sempre a incorporar novos valores e juízos éticos. Sendo assim, a sustentabilidade, também, diante do discurso dos direitos fundamentais pode seguir uma evolução no sentido de agregar novas dimensões. Aloe (2010) e Cabral (2011) chamam a atenção para todos os assuntos que permeiam o ser humano enquanto vivente do planeta Terra e que estariam dentro da expansão da ideia de sustentabilidade para a integralidade. Dessa forma, o ser humano passa a ser considerado como o foco de análise e dentro de uma perspectiva integral, ou de completude, incorporadora de quatro dimensões: social, ambiental, econômico e visão de mundo. A expansão das dimensões da sustentabilidade trabalha, portanto, a expansão da consciência do indivíduo, ou seja, da responsabilidade individual ao comprometimento social explicitados em Sen (2000).

A integralidade como proposta de expansão das dimensões da sustentabilidade corrobora com a visão de Sachs (2002) sobre a validade das dimensões do desenvolvimento sustentável, debatidos nas Conferências de Estocolmo e do Rio, quais sejam, social, cultural, ecológica, ambiental, territorial, econômica, política nacional e política internacional. Porém, a sustentabilidade integral propõe a absorção de algumas dessas dimensões no âmbito da visão de mundo para tornar transparente a ideia de expansão da consciência humana, trazendo para o ser humano a perspectiva de sua responsabilidade consigo, com as demais pessoas, com o território em que vive e com o planeta Terra. Nessa linha lógica, os elementos ${ }^{7}$ constantes do Our Common Future (WCED, 1987) para o desenvolvimento sustentável estariam, também, sendo agregados à integralidade enquanto expansão das dimensões de sustentabilidade. Assim, a responsabilidade individual, o comprometimento social e a solidariedade seriam os valores primordiais nessa nova abordagem das dimensões da sustentabilidade que se agrega à noção do princípio da justiça intra e intergeracional.

A responsabilidade considera o indivíduo como agente, e não sujeito pas- 
sivo da realidade que o cerca e as implicações que suas decisões acarretam para seu entorno. $\mathrm{O}$ comprometimento social abarca a justiça ou a equidade intergeracional, baseada no fato de que em "qualquer momento, cada geração é ao mesmo tempo guardiã ou depositária da terra e sua usufrutuária: beneficiário de seus frutos", o que impõe a obrigação de cuidar do planeta (Weiss, 1993, p.15). E a solidariedade traz como conteúdo a aptidão de compreensão das necessidades humanas de modo a expandir as possibilidades de efetivação de direitos fundamentais quando se comungam e se compartilham problemas e interesses semelhantes diante da escassez de recursos naturais do planeta, corroborando com o ideal de que os bens ambientais, por exemplo, devem ser partilhados equitativamente pelas gerações sucessivas.

Do que se depreende que as desigualdades existentes no século XXI possibilitam o diálogo entre necessidades humanas, sustentabilidade e direitos fundamentais, que através de contínua expansão permite o alcance da concretização do princípio da justiça intra e intergeracional, em especial, quando se está perante a decisão de quais os setores e/ou segmentos que devem perceber receitas advindas da exploração de recursos naturais finitos, como o petróleo e o gás natural.

Assim, a unicidade do princípio da justiça intra e intergeracional parte da mesma ideia construída pela teoria dos direitos fundamentais, compreendendo que a utilização da expressão "geração de direitos" dá menção de uma geração superar a outra, ou mesmo se sobrepor, quando na realidade não existe isso, $o$ que há é continuidade, acréscimo, cumulatividade de "gerações" e, portanto, unicidade da experiência humana sobre a Terra. Então, diante da perspectiva da ampliação das dimensões da sustentabilidade e da contínua expansão do rol de direitos fundamentais, assume-se que as necessidades humanas se imiscuem ao conteúdo desses direitos e da sustentabilidade integral. Assim, ao se correlacionar o conceito de princípio da justiça intra e intergeracional com o conteúdo da sustentabilidade integral e dos direitos fundamentais, considera-se, igualmente, o alargamento contínuo desse princípio.

Do ponto de vista prático, o princípio justiça intra e intergeracional traz que inúmeras são as formas de tornar o seu conteúdo concreto. No presente trabalho, a efetivação desse princípio pauta-se pela espacialização do desenvolvimento e pela compreensão do funcionamento do território para propor a reflexão de uma lista flexível de prioridades de investimentos, bem como considerando o mapeamento socioespacial, em uma lista igualmente flexível de necessidades das localidades estudadas, que leve em conta o nível da qualidade de vida dessa população. Destaca-se, igualmente, a participação popular como procedimento imprescindível para essa metodologia descrita, sobretudo, ao se assumir a responsabilidade individual, o comprometimento social (ou corresponsabilidade) e a solidariedade como valores a ser perseguidos no âmbito de políticas públicas.

Diante de tais perspectivas, ter-se-á uma visão do lugar ou da região, de suas conexões com problemas específicos de natureza socioespacial e da própria 
qualidade de vida daquela população. Uma política pública decorrente dessa lógica terá como mérito a visão do território e as nuanças que se fazem necessárias para progressiva incorporação da sustentabilidade integral e da efetivação dos direitos fundamentais na vida da população em questão. A efetivação do princípio da justiça intra e intergeracional equivale, dessa maneira, a visualizar e a avaliar cada território, sem perseguir uma fórmula única, mas sim guardando o respeito à especificidade de cada localidade destinatária das rendas de hidrocarbonetos.

A destinação das rendas de hidrocarbonetos vinculada aos direitos fundamentais e à sustentabilidade integral, portanto, permite a efetivação do princípio da justiça intra e intergeracional, pois soluciona, no presente, graves problemas de concepção do ser humano acerca de suas reais necessidades.

\section{Considerações finais}

Em termos de considerações finais, deseja-se salientar que o conceito de princípio da justiça intra e intergeracional, defendido no presente trabalho como único, dá ampla conectividade à visão de completude do ser humano ao longo do tempo. A ideia central desse princípio é concretizar a sustentabilidade integral das sucessivas gerações de seres humanos que vivem no globo terrestre através da efetivação de direitos fundamentais.

Tendo por objetivo aproveitar a potencialidade das rendas de hidrocarbonetos, propôs-se a responder a seguinte pergunta: quais as necessidades humanas que proporcionam o cumprimento do princípio da justiça intra e intergeracional quando da destinação dessas rendas? A resposta se construiu no sentido de que se faz imprescindível uma metodologia com base no conhecimento das necessidades territoriais, que concretizem a sustentabilidade integral e os direitos fundamentais das sucessivas gerações.

Também, constatou-se que a indústria de hidrocarbonetos, sobretudo, por ser intrinsecamente relacionada a recursos naturais não renováveis, tem um importante papel a desempenhar no tocante à efetivação do princípio da justiça intra e intergeracional, pois proporciona o despertar humano para sua relação com o planeta Terra. Primeiramente, pelo motivo de abrir o debate acerca de quais recursos energéticos substitutos podem ser economicamente explorados. Em segundo lugar, por permitir a discussão a respeito da responsabilidade individual, do comprometimento social (ou corresponsabilidade) e da solidariedade do ser humano em termos de continuidade e qualidade da vida na Terra. Em terceiro lugar, por proporcionar a entrada de receitas financeiras para o Estado e para a economia local, que, caso sejam corretamente destinadas, proporcionarão o desenvolvimento humano da população em questão.

Com isso, as políticas públicas, e o seu estigma conceitual, poderão contar com aparatos informacionais que promovam a efetivação dos direitos fundamentais e da sustentabilidade integral, que formam o conteúdo do princípio da justiça intra e intergeracional. 
Notas

1 São quatro as participações governamentais: bônus de assinatura, royalties, participação especial, pagamento pela ocupação ou retenção de área (artigo 45 da Lei n. 9.478/97).

2 As premissas utilizadas por Hartwick (1977) envolvem economias que, somente, contam com um único tipo de recurso mineral exaurível, não possuem poupança proveniente do setor industrial, bem como sua população permaneceria constante.

$3 \mathrm{O}$ rol de direitos fundamentais sociais está descrito no art. $6^{\circ}$ da $\mathrm{CF} / 88$, são eles: direitos sociais a educação, saúde, alimentação, trabalho, moradia, lazer, segurança, previdência social, proteção à maternidade e à infância, assistência aos desamparados. Interessante salientar que essa autora incluiu o direito ao meio ambiente nesse rol de direitos fundamentais sociais, de segunda dimensão, vinculados à ideia de igualdade da Revolução Francesa.

4 O termo empregado "dimensões" tem preponderado no âmbito do estudo dos direitos fundamentais, considerando o reconhecimento progressivo de novos direitos e com caráter cumulativo. A expressão "gerações" foi apontada como de uma percepção de substituição de uma geração por outra geração (Sarlet, 2007, p.54).

$5 \mathrm{O}$ ser humano necessita, para viver, de uma quantidade de calorias diariamente, que possibilite a realização de todo o seu potencial. Na sociedade atual, a busca do alimento se tornou uma troca (trabalho x mercadoria), para tanto o indivíduo precisa de uma renda diária que supra tais necessidades biológicas de alimentação. Ao mesmo tempo, o ser humano precisa de educação, saúde, incluindo o saneamento, dentre outras necessidades vitais. Goldemberg e Villanueva (2003, p.44-5), por exemplo, dizem que o homem primitivo (do Leste da África), sem considerar o uso do fogo, consumia diariamente 2 mil kcal, já o homem tecnológico (tendo por base a vida nos Estados Unidos em 1970) consumia, cerca de 230 mil kcal, levando-se em conta os usos energéticos na alimentação, na moradia e comércio, indústria e agricultura e transporte.

6 No âmbito da progressiva incorporação de direitos fundamentais, encontram-se os da quarta dimensão, decorrentes de uma extensão dos direitos de primeira dimensão, e compreendendo os direitos à democracia, à informação e ao pluralismo (Bonavides, 2010 , p.571). Inclusive, Bonavides (2010) já trata de uma quinta dimensão de direitos fundamentais, consistente no direito à paz, que migraria da terceira para a quinta dimensão, em virtude da sua expansão e importância crescentes.

7 Os elementos citados pelo Our Common Future são: crescimento econômico sustentável; mudanças de qualidade nesse crescimento econômico; atendimento às necessidades essenciais das comunidades; garantir crescimentos populacionais sustentáveis; reproduzir e conservar a base de recursos naturais; orientação adequada da tecnologia e da gestão do risco; fusão dos aspectos econômicos com os sociais e ambientais.

\section{Referências}

ALOE, G. O que é sustentabilidade? Entrevista realizada em 23 de outubro de 2010, Centro de Sustentabilidade, Fundação Alphaville, Santana do Parnaíba, São Paulo, 2010 .

BARBIERI, J. C. Desenvolvimento e meio ambiente: as estratégias de mudanças da Agenda 21. 7.ed. Petrópolis: Vozes, 2005.

BOBBIO, N. A era dos direitos. Rio de Janeiro: Elsevier, 2004. 
BONAVIDES, P. Curso de direito constitucional. 22.ed. São Paulo: Malheiros, 2010.

BREGMAN, D. Formação, distribuição e aplicação de royalties de recursos naturais: o caso do petróleo no Brasil. 2007. Dissertação (Mestrado em Economia) - Instituto de Economia, Universidade Federal do Rio de Janeiro. Rio de Janeiro, 2007.

CABRAL, W. Sustentabilidade Integral. Disponível em: <http://stoa.usp.br/wagnerk/files/-1/16705/trabalho+de+STPP+-+professor+Cabral.pdf $>$. Acesso em: 10 out. 2011.

CARVALHO, F. C. L. Aspectos éticos da exploração do petróleo: os royalties e a questão intergeracional. 2008. Dissertação (Mestrado em Planejamento Energético) - Coordenação dos Programas de Pós-Graduação de Engenharia (COPPE), Universidade Federal do Rio de Janeiro. Rio de Janeiro, 2008.

CARVALHO, J. F. O declínio da era do petróleo e a transição da matriz energética brasileira para um modelo sustentável. 2009. Tese (Doutorado em Energia) - Instituto de Eletrotécnica e Energia, Universidade de São Paulo. São Paulo, 2009.

DAVIS, A. G.; TILTON, J. E. The resource curse. Natural Resources Forum, n.29, p.233-242, 2005.

DORNELAS, H. L.; BRANDÃO, E. J. Justiça ambiental e equidade intergeracional: a proteção dos direitos das gerações futuras. Jus Navegandi, Teresina, ano 16, n.2876, 17 maio 2011. Disponível em: <http://jus.com.br/revista/texto/19129>. Acesso em: 18 maio 2011.

FYFE, W. S. As ciências da Terra e a sociedade: as necessidades para o século XXI. Estudos Avançados, São Paulo, v.11, n.30, p.175-90, 1997.

GOLDEMBERG, J.; VILLANUEVA, L. D. Energia, meio ambiente \& desenvolvimento. Trad. André Koch. 2.ed. São Paulo: Editora da Universidade de São Paulo, 2003.

HARTWICK, J. M. Intergenerational Equity and the Investing of Rents from Exhaustible Resources. The American Economic Review, v.67, n.5, p.972-74, dec. 1977. Disponível em: <http://www.jstor.org/stable/1828079>. Acesso em: 27.5.2009.

HERCULANO, S. Riscos e desigualdade social: a temática da Justiça Ambiental e sua construção no Brasil. In: I ENCONTRO DA ANPPAS - Indaiatuba, São Paulo, GT Teoria e Ambiente. Disponível em: <http://www.anppas.org.br/encontro_anual/encontrol/gt/teoria_meio_ambiente/Selene\%20Herculano.pdf>. Acesso em: 20 ago. 2010.

JIMÉNEZ, A. M. Justicia ambiental. Del concepto a la aplicación en planificación y análisis de políticas territoriales. Scripta Nova. Revista Electrónica de Geografía y Ciencias Sociales. [En línea], Barcelona, v.XIV, n.316. 1ํ marzo 2010. Disponível em: <http:// www.ub.es/geocrit/sn/sn-316.html>. Acesso em: 20 maio 2010.

MENDONÇA, F. de A. Geografia e meio ambiente. 8.ed. São Paulo: Contexto, 2005.

MENON, M. G. K. O papel da ciência no desenvolvimento sustentável. Revista de Estudos Avançados, v.6, n.15, p.123-7, 1992.

MOUTINHO DOS SANTOS, E. Energia, gás natural \& sustentabilidade. 2004. Tese (Livre-Docência em Energia) - Instituto de Eletrotécnica e Energia, Universidade de São Paulo. São Paulo, 2004.

NUSDEO, A. M. Justiça Ambiental. Disponível em: <http://www.esmpu.gov.br/dicionario/tiki-index.php?page=justi\%C3\%A7a+ambiental>. Acesso em: 20 out. 2010. 
OLIVEIRA, F. P. M.; GUIMARÃES, F. Direito, meio ambiente e cidadania: uma abordagem interdisciplinar. São Paulo: Madras, 2004.

PACHECO, C. A. G. Avaliação de critérios de distribuição e de utilização de recursos das participações governamentais no Brasil. 2007. Dissertação (Mestrado em Planejamento Energético) - Coordenação dos Programas de Pós-Graduação de Engenharia (COPPE), Universidade Federal do Rio de Janeiro. Rio de Janeiro, 2007.

PRZEPIORKA, E. Quais as necessidades humanas? Entrevista realizada em 23 de outubro de 2010. Centro de Sustentabilidade, Fundação Alphaville. Santana do Paranaíba, 2010.

RIBEIRO, W. C. Geografia política e gestão internacional dos recursos naturais. Revista de Estudos Avançados, v.24, n.68, p.69-80, 2010.

SACHS, I. Desenvolvimento, direitos humanos e cidadania. Instituto de Pesquisa de Relações Internacionais Fundação Alexandre Gusmão. Seminário Direitos Humanos no Século XXI, 10 e 11 de setembro de 1998, Rio de Janeiro. Disponível em: <www.mre. gov.br/ipri>. Acesso em: 25 mar. 2008.

2002.

. Caminhos para o desenvolvimento sustentável. Rio de Janeiro: Garamond,

Prefácio da obra de José Eli da Veiga. In: VEIGA, J. E. Desenvolvimento sustentável: o desafio do século XXI. 2.ed. Rio de Janeiro: Garamond, 2006.

SANTOS, M. 1992: a redescoberta da Natureza. Estudos Avançados, São Paulo, v.6, n.14, p.96-106, 1992.

SARLET, I. W. A eficácia dos direitos fundamentais. 8.ed. Porto Alegre: Livraria do Advogado, 2007.

SEN, A. Desenvolvimento como liberdade. São Paulo: Cia. das Letras, 2000.

SERRA, R. V. Contribuições para o debate acerca da repartição dos royalties petrolíferos no Brasil. 2005. Tese (Doutorado em Economia Aplicada) - Instituto de Economia, Universidade Estadual de Campinas. Campinas, 2005.

Concentração espacial das rendas petrolíferas e sobrefinanciamento das esferas de governo locais. In: PIQUET, R.; SERRA, R. (Org.) Petróleo e região no Brasil: o desafio da abundância. Rio de Janeiro: Garamond, 2007. p.77-108.

SOUZA, M. A. A. de. Meio ambiente e desenvolvimento sustentável. As metáforas do capitalismo. Professora Titular de Geografia Humana (Disciplina Planejamento) da USP e Presidente do TERRITORIAL Instituto de Pesquisa, Informação e Planejamento, Palestra proferida em 2002.

TORRONTEGUY, A. F. A aplicação dos royalties do petróleo e a efetividades dos direitos fundamentais sociais. 2009. Dissertação (Mestrado em Direito) - Programa de Pós-Graduação em Direitos e Garantias Fundamentais, Faculdade de Direito de Vitória. Vitória, 2009.

VARGAS, J. I. Energia como fator limite para o desenvolvimento sustentável. Estudos Avançados, São Paulo, v.10, n.27, p.295-306, 1996.

VEIGA, J. E. Desenvolvimento sustentável: o desafio do século XXI. 2.ed. Rio de Janeiro: Garamond, 2006. 
WCED - World Commission on Environment and Development. 1987. Our Common Future. Oxford University Press, Oxford.

WEISS, E. B. Justice pour les générations futures. Paris: Editions Sang de la Terre, 1993.

RESUMO - O presente artigo objetiva a construção do princípio da justiça intra e intergeracional ao propor a abordagem unitária das sucessivas gerações humanas para fins da normatização da destinação de participações governamentais decorrentes da produção de hidrocarbonetos. Assume-se como objetivo básico das políticas públicas a sustentabilidade da vida com qualidade no globo terrestre. Assim, defende-se que a destinação das rendas de hidrocarbonetos em políticas públicas deve refletir as necessidades de cada localidade beneficiária, considerando a vocação de seu desenvolvimento territorial, bem como a sustentabilidade integral e a efetivação dos direitos fundamentais da sua população.

PALAVRAS-CHAVE: Produção de hidrocarbonetos, Destinação de participações governamentais, Princípio da justiça intra e intergeracional, Sustentabilidade, Direitos fundamentais.

ABSTRACT - This paper aims to define the principle of justice intrageneration and intergeneration by creating the idea of the humankind as one. It proposes the principle as a standard of the allocation of the government takes from the production of hydrocarbons. It assumes as a basic purpose of the public policies the sustainability of quality of life on the Earth. Thus, it argues that the allocation of the government take on public policies should reflect the needs of each place, considering the vocation of its territorial development, as well as the integral sustainability and the enforcement of fundamental rights of its population.

KEYWORDS: Production of hydrocarbons, Allocation of government takes, Principle of justice intrageneration and intergeneration, Sustainability, Fundamental rights.

Hirdan Katarina de Medeiros Costa é advogada, doutoranda no Programa de Pós-Graduação em Energia da Universidade de São Paulo, bolsista de doutorado do CNPq. @-hirdan@usp.br

Edmilson Moutinho dos Santos é professor doutor do Programa de Pós-Graduação em Energia da Universidade de São Paulo. @- edsantos@iee.usp.br

Recebido em 2.3.2011 e aceito em 26.6.2012. 